\title{
Airborne-radar and ice-core observations of annual snow accumulation over Thwaites Glacier, West Antarctica confirm the spatiotemporal variability of global and regional atmospheric models
}

\author{
B. Medley, ${ }^{1,2}$ I. Joughin, ${ }^{2}$ S. B. Das, ${ }^{3}$ E. J. Steig, ${ }^{1,4}$ H. Conway, ${ }^{1}$ S. Gogineni, ${ }^{5}$ \\ A. S. Criscitiello, ${ }^{3,6}$ J. R. McConnell, ${ }^{7}$ B. E. Smith, ${ }^{2}$ M. R. van den Broeke, ${ }^{8}$ \\ J. T. M. Lenaerts, ${ }^{8}$ D. H. Bromwich, ${ }^{9}$ and J. P. Nicolas ${ }^{9}$
}

Received 28 April 2013; revised 26 June 2013; accepted 28 June 2013; published 26 July 2013.

[1] We use an airborne-radar method, verified with ice-core accumulation records, to determine the spatiotemporal variations of snow accumulation over Thwaites Glacier, West Antarctica between 1980 and 2009. We also present a regional evaluation of modeled accumulation in Antarctica. Comparisons between radar-derived measurements and model outputs show that three global models capture the interannual variability well $(r>0.9)$, but a high-resolution regional model (RACMO2) has better absolute accuracy and captures the observed spatial variability $(r=0.86)$. Neither the measured nor modeled accumulation records over Thwaites Glacier show any trend since 1980. Although an increase in accumulation may potentially accompany the observed warming in the region, the projected trend is too small to detect over the 30 year record. Citation: Medley, B. et al. (2013), Airborne-radar and ice-core observations of annual snow accumulation over Thwaites Glacier, West Antarctica confirm the spatiotemporal variability of global and regional atmospheric models, Geophys. Res. Lett., 40, 3649-3654, doi:10.1002/grl.50706.

Additional supporting information may be found in the online version of this article.

${ }^{1}$ Earth and Space Sciences, University of Washington, Seattle, Washington, USA

${ }^{2}$ Polar Science Center, Applied Physics Lab, University of Washington, Seattle, Washington, USA.

${ }^{3}$ Geology and Geophysics, Woods Hole Oceanographic Institution, Woods Hole, Massachusetts, USA.

${ }^{4}$ Quaternary Research Center, University of Washington, Seattle, Washington, USA.

${ }^{5}$ Center for Remote Sensing of Ice Sheets, University of Kansas, Lawrence, Kansas, USA.

${ }^{6}$ MIT/WHOI Joint Program in Oceanography/Applied Ocean Sciences and Engineering, Woods Hole Oceanographic Institution, Woods Hole, Massachusetts, USA.

${ }^{7}$ Desert Research Institute, Nevada System of Higher Education, Reno, Nevada, USA.

${ }^{8}$ Institute for Marine and Atmospheric Research Utrecht, Utrecht University, Utrecht, Netherlands.

${ }^{9}$ Polar Meteorology Group, Byrd Polar Research Center, Atmospheric Sciences Program, Department of Geography, Ohio State University, Columbus, Ohio, USA.

Corresponding author: B. Medley, Department of Earth and Space Sciences, University of Washington, Seattle, WA 98195, USA. (bmed@uw.edu)

(C2013. American Geophysical Union. All Rights Reserved. 0094-8276/13/10.1002/grl.50706

\section{Introduction}

[2] In Antarctica, where snowmelt and runoff are small, the competing processes of mass gain through snow accumulation and loss through ice discharge to the ocean control the ice sheet's net mass balance and thus its contribution to sea level. Here we use accumulation interchangeably with surface mass balance (SMB), which is defined as snowfall minus sublimation and meltwater runoff and includes drifting snow processes. Basin-wide accumulation is a large source of uncertainty in regional mass loss estimates. For example, both observation- and model-based basin-wide accumulation climatologies [van de Berg et al., 2005; Arthern et al., 2006; Monaghan et al., 2006] over Pine Island and Thwaites Glaciers vary from 129 to $182 \mathrm{Gt} \mathrm{yr}^{-1}$, a range that is comparable to the net mass loss [Rignot et al., 2008]. The mass balance of the Amundsen Coast region is of particular interest because recent accelerated ice discharge from Pine Island and Thwaites Glaciers to the ocean makes the region one of the largest Antarctic contributors to current sea-level rise [Shepherd et al., 2012; Rignot et al., 2008].

[3] Under a warming climate, the associated increase in atmospheric moisture content is expected to increase ice sheet snow accumulation [Genthon et al., 2009], but modeling studies [Monaghan et al., 2006; Lenaerts et al., 2012] do not show this trend, despite significant warming in West Antarctica over recent decades [Steig et al., 2009; Orsi et al., 2012; Bromwich et al., 2013]. Although ice cores provide long-term accumulation records, their sparse distribution undersamples the spatial variability. In West Antarctica, only a few high-elevation (>1200 m asl) annually resolved ice core accumulation records exist: several from ITASE in the early 2000s [Kaspari et al., 2004] and three cores (PIG2010, DIV2010, and THW2010) recovered in 2010/2011 (Figure 1). None are from lowelevation coastal sites where accumulation is the highest. Furthermore, substantial small-scale accumulation variability suggests that individual cores do not adequately represent regional accumulation [Banta et al., 2008].

[4] This work uses a newly developed airborne radar system, referred to as the "snow radar" [Panzer et al., 2013], with bandwidth sufficient to resolve near-surface stratigraphy continuously over hundreds of kilometers along aircraft flight paths (Figure 2). This radar is a frequencymodulated continuous wave system developed by the Center for Remote Sensing of Ice Sheets (CReSIS) and flown on NASA's Operation IceBridge campaign 


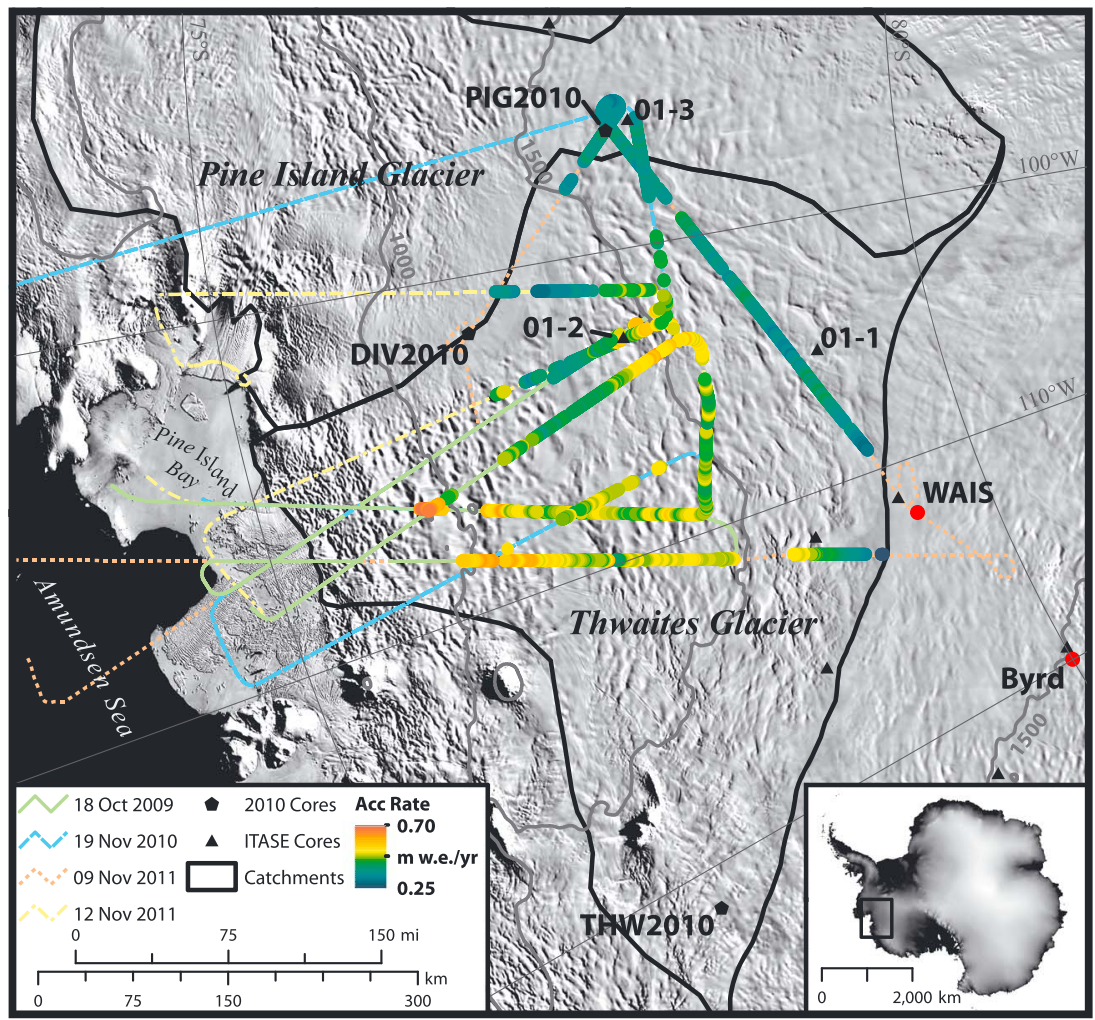

Figure 1. Thirty-year average accumulation rates and select Operation IceBridge flight paths overlaid on a MODIS mosaic [Haran et al., 2005]. The inset map outlines the study area relative to a digital elevation model of Antarctica [Bamber et al., 2009]. The catchments are outlined in black. Elevation contours (m) are labeled accordingly. The ITASE cores collected between 2000 and 2001 are shown as triangles and cores collected in 2010/2011 are shown as pentagons. Red circles show the major field camps.

[Leuschen, 2010; Rodriguez-Morales et al., 2013]. During the 2009 campaign, the system operated over the 4-6 $\mathrm{GHz}$ frequency range (vertical resolution $\sim 10 \mathrm{~cm}$ ); in 2010 and 2011, it operated over the 2-6.5 GHz frequency range (vertical resolution $\sim 5 \mathrm{~cm}$ ). We stacked traces to a horizontal resolution of $\sim 55 \mathrm{~m}$. The radar documentation and data are available at ftp://data.cresis.ku.edu/data/snow. The radar reflection horizons (Figure 2) represent contrasts in the material's dielectric permittivity, attributed to isochronous buried sequences of hoar layers and associated ice crusts [Arcone et al., 2004, 2005a, 2005b; Spikes et al., 2004]. The roughly annual occurrence of such sequences and the fine vertical radar resolution indicate that these horizons can be dated. Using these data with a regional firn depth-density model, we derive annual accumulation records from 1980 to 2009 along each radar profile [c.f. Kanagaratnam et al., 2004] over most of the Thwaites basin $\left(\sim 182 \mathrm{Mkm}^{2}\right)$.

\section{Methods}

[5] Calculating spatiotemporal accumulation rates using airborne radar requires three data sets: (1) a firn depth-density profile, (2) radar-profiled isochrones, and (3) a depth-age profile to determine isochrone ages. The water-equivalent accumulation rate $\left(\mathrm{m}\right.$ w.e. $\left.\mathrm{yr}^{-1}\right)$ between two mapped isochrones (i.e., over a discrete time period) is

$$
\dot{b}(x)=\Delta C M(x) /\left(\Delta t \cdot \rho_{w}\right)
$$

where $x$ is location along the flight path, $\triangle C M$ is the cumulative mass per unit area $\left(\mathrm{kg} \mathrm{m}^{-2}\right)$ between two isochrones that differ $\Delta t$ in age, and $\rho_{w}$ is the density of water $\left(1000 \mathrm{~kg} \mathrm{~m}^{-3}\right)$. The mapped horizons are assumed to be annual isochrones, and thus $\Delta t$ is independent of $x$ and equal to 1 year. Although we employ a single cumulative mass profile

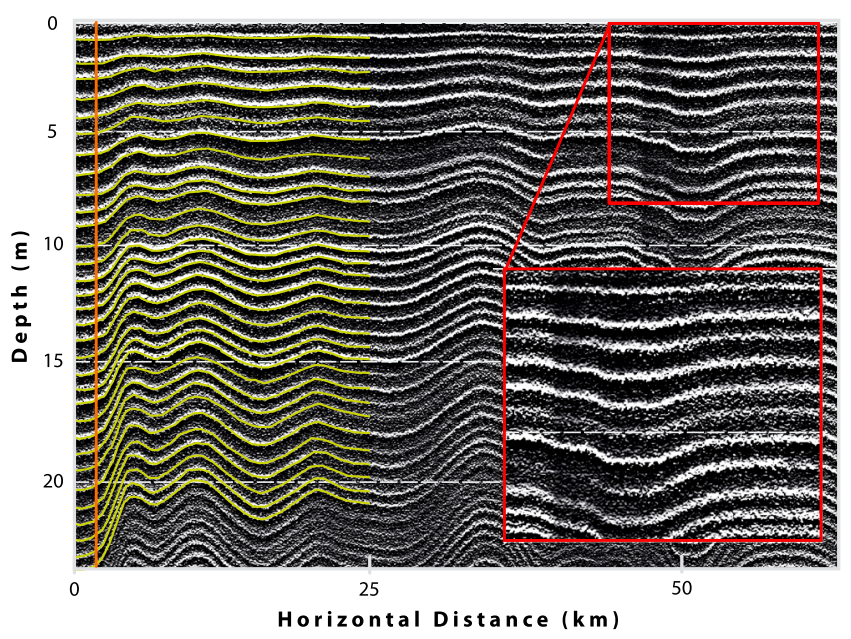

Figure 2. Sample snow radargram partly overlaid by manual horizon picks. The vertical orange line shows the location of the PIG2010 ice core. These data were collected on 9 November 2011 and show the consistency of horizons over large distances. Inset shows detail in the upper $\sim 7 \mathrm{~m}$ outlined in red. 
for the entire region, $\triangle C M$ varies along the flight path because the isochrones vary in depth.

\subsection{Firn Density Profile}

[6] A firn depth-density profile is needed to convert radar measurements of two-way travel time $\tau$ to depth $d$ and to calculate a cumulative mass profile. Although firn densification varies with temperature and accumulation rate, here we use a single profile for the entire basin. We fit a steady-state density model [Herron and Langway, 1980] to the mean of nine firn-core density profiles from the region (Figure S1). We use a mixture model [Looyenga, 1965] to calculate the dielectric permittivity $\varepsilon_{d}$ of the firn and calculate depth from the measured two-way travel time: $d=0.5 c \tau \varepsilon_{d}{ }^{-0.5}$, where $c$ is the wave speed in a vacuum $\left(3 \times 10^{8} \mathrm{~m} \mathrm{~s}^{-1}\right)$. The $d$ - $\tau$ profile is calculated at $1 \mathrm{~cm}$ intervals to account for the depth variations of density and dielectric permittivity. The cumulative mass profile is calculated by integrating the modeled density profile.

\subsection{Snow-Radar Accumulation Rate Error Estimation}

[7] The radar-derived accumulation rate error estimates account for the regional variation in the firn density profile and the uncertainty in the horizon time interval $\Delta t$ (see Supporting Information). The error resulting from density variation is based on the model fits to the $\pm 1 \sigma$ variation in density profile from the mean (Figure S1). We also assume an error in $\Delta t$ of \pm 1 month, as the time of creation of the isochrones likely varies. A digitization error of 1 radar sample is included, equivalent to approximately 3 and $6 \mathrm{~cm}$ for the 2010/2011 and 2009 flights, respectively. The typical accumulation rate measurement error is less than $\pm 10 \%$, except for the most recent years (i.e., layers near the surface) when errors approach $\pm 15 \%$ (Figure S2). Spatial averaging minimizes the impact of these errors and reduces the annual accumulation error to less than $\pm 5 \%$.

\subsection{Ice Core Analysis}

[8] Water isotope ratios and more than 30 elements and chemical species were measured at high depth resolution $(\sim 1 \mathrm{~cm}$ w.e. $)$ using a continuous ice core melter system [McConnell et al., 2002, 2007; Maselli et al., 2013]. While nearly all ratios exhibit pronounced annual cycles in concentration, here we used the summer maxima in hydrogen peroxide concentration, water isotope ratios, and nonsea-salt sulfur to sodium ratio to identify consistent annual layers. Well-known volcanic horizons identified by marked increases in wintertime sulfur concentration were used to verify the annual layer counting, which indicated a dating uncertainty of $<1$ year.

\subsection{Method Validation}

[9] Snow-radar horizons were dated by counting horizons assumed to be annual. To verify this assumption, we compare the snow-radar accumulation record with that from the nearly colocated ( $\sim 50$ m separation) PIG2010 ice core (Figure S3). The 30 year averages ( \pm 1 standard deviation) of $0.424 \pm 0.065 \mathrm{~m}$ w.e. $\mathrm{yr}^{-1}$ from the core and $0.428 \pm 0.055$ $\mathrm{m}$ w.e. $\mathrm{yr}^{-1}$ from the radar are indistinguishable. Annual layer thicknesses are highly correlated $(r=0.85)$, validating our assumption that the radar resolves horizons with annual resolution and indicating that the snow-radar accumulation records are consistent with the ice core records. All calculated correlation coefficients are statistically significant at the $99 \%$ confidence level, accounting for autocorrelation. Comparisons between individual ice core records and the radar- and model-derived records are displayed in Figures S4-S7.

\section{Results}

\subsection{Radar-Derived Accumulation Rates}

[10] Using four radar surveys collected between 2009 and 2011 over an area of $\sim 350 \mathrm{~km} \times \sim 350 \mathrm{~km}$, we generated 30 year accumulation records at $250 \mathrm{~m}$ intervals along track (Figure 1). The 30 year average accumulation rates vary spatially between $0.27 \mathrm{~m}$ w.e. $\mathrm{yr}^{-1}$ in the high-elevation interior and $0.67 \mathrm{~m} \mathrm{w} . \mathrm{er}^{-1}$ near the coast. The spatial mean is $0.457 \pm 0.066 \mathrm{~m}$ w.e. $\mathrm{yr}^{-1}$, and elevations sampled ranged from 950 and $1840 \mathrm{~m}$ asl. Strong accumulation variability is associated with the slope-dependent effect of wind-driven snow redistribution [Arcone et al., 2005b], which is clearly visible in our data because the greatest accumulation variability corresponds with strongly varying surface slopes, as indicated by tonal variations in the basemap in Figure 1. Missing data along the flight paths indicate the 30 year accumulation record is incomplete (i.e., one or more of the 30 annual horizons could not be digitized). These data gaps could introduce a magnitude bias in our regional record, which is acceptable because we are not attempting to determine basin-wide accumulation and instead are interested in its variability and trend.

[11] We created a regional accumulation record by spatially averaging all radar-derived records (Figure 3). Between 1980 and 2009, the average accumulation rate is $0.457 \pm 0.055 \mathrm{~m}$ w.e. $\mathrm{yr}^{-1}$, and the record shows no significant trend. We created two three-core accumulation rate ensembles using our 2010/2011 ice core records and the ITASE records [Kaspari et al., 2004] to produce independent quasi-regional records for comparison with the snow-radar record (Figure 3). The ensembles have slightly lower mean accumulation rates than the snow-radar record, yet correlate significantly $(r=0.80$; Table 1$)$. This comparison with ice core data indicates that the snow radar provides accurate accumulation estimates.

\subsection{Atmospheric Model Validation}

[12] Model-derived snow accumulation is increasingly being used in place of observations. Our data provide an opportunity to evaluate the skill of such models at a regional scale and at annual resolution. We compared our data with three global reanalysis precipitation-minus-sublimation $(P-S)$ products [Bromwich et al., 2011] of varying grid resolutions (see Table 1): the European Centre for Medium-Range Weather Forecasts "Interim" (ERAInterim) [Dee et al., 2011], the NASA Modern Era Retrospective Analysis for Research and Applications (MERRA) [Rienecker et al., 2011], and the National Centers for Environmental Prediction Climate Forecast System Reanalysis (CFSR) [Saha et al., 2010]. We also used SMB from the Regional Atmospheric Climate Model v.2.1 (RACMO2) [Lenaerts et al., 2012], which is forced on its lateral boundary with the ERA-Interim reanalysis. The reanalysis $P-S$ products are nearly equivalent to SMB in this region because runoff is negligible and drifting snow processes typically amount to less than 


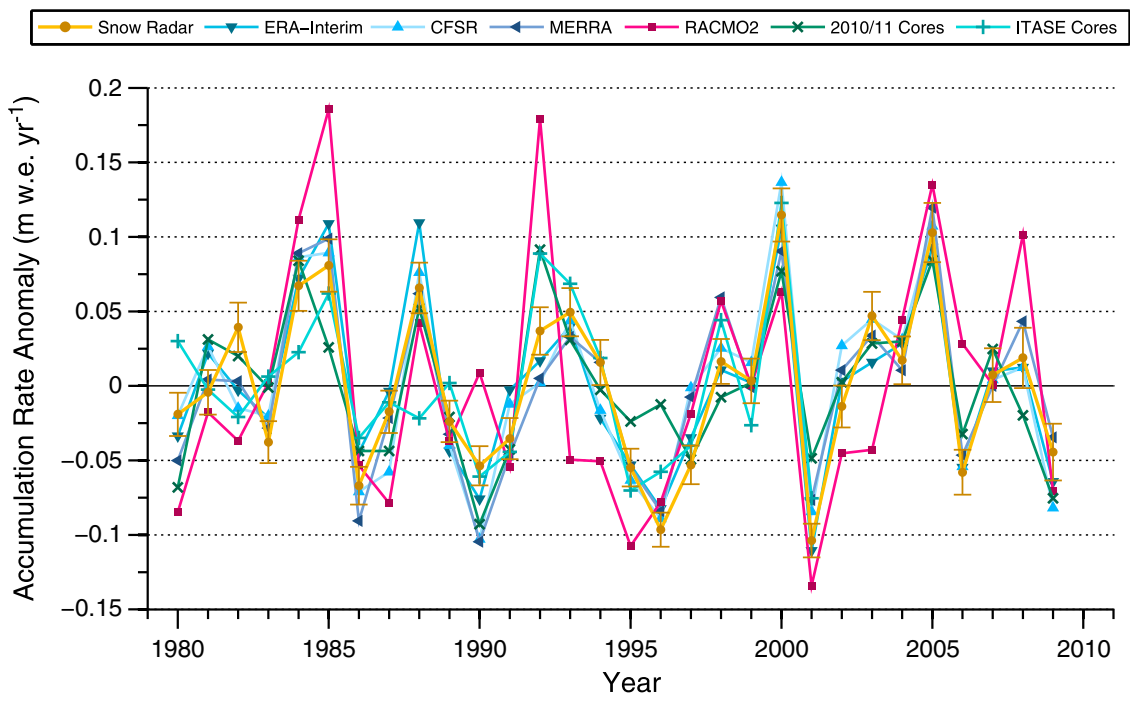

Figure 3. Comparison of the accumulation rate anomalies derived from the snow radar (orange circles), the 2010/2011 $($ green $\times$ ) and ITASE (blue-green + ) core ensembles, RACMO2 (red squares), and three global reanalyses (blue triangles). The snow-radar record is the spatial average of all complete records shown in Figure 1 and includes $1-\sigma$ error bars. The 2010 core ensemble is the average of the PIG2010, DIV2010, and THW2010 cores, which have age uncertainties of $<1$ year. The ITASE ensemble is the average of the ITASE $01-1,01-2$, and $01-3$ core records, which have age uncertainties of $\leq 1$ year. All anomalies were estimated by subtracting the long-term (1980-2009) mean, which are listed in Table 1.

$6 \%$ of the total, based on analysis of the RACMO2 SMB components. We generated regional records of modeled accumulation (equivalent to $P-S$ ) by taking the average of grid cell records weighted by the percentage of snow-radar records within each cell. Figure 3 shows the regional snow radar and model-derived records as anomalies from their respective 1980-2009 means shown in Table 1. The RACMO2 30 year average accumulation rate of $0.434 \pm 0.080 \mathrm{~m}$ w.e. $\mathrm{yr}^{-1}$ is slightly less than the snow-radar average of $0.457 \pm 0.055 \mathrm{~m}$ w.e. $\mathrm{yr}^{-1}$. The global reanalyses have even lower averages between $0.346 \pm 0.057$ and $0.407 \pm 0.060 \mathrm{~m}$ w.e. $\mathrm{yr}^{-1}$. The correlation coefficients shown in Table 1 indicate that the global reanalyses are highly correlated temporally $(r>0.9)$ and RACMO2 is moderately correlated $(r=0.68)$ with the snow-radar record. The global reanalyses are moderately correlated spatially with correlation coefficients ranging between 0.68 and 0.75 , whereas RACMO2 is highly correlated $(r=0.86)$.
[13] The agreement between the models and the snow radar indicates that the models reasonably capture the magnitude and variability of accumulation in this sector of West Antarctica, but with notable deficiencies. RACMO2 adequately reproduces the mean annual accumulation, while the global reanalyses are biased low. The interannual accumulation variability is accurately reproduced by the reanalysis products, while RACMO2 exhibits exaggerated variability; its standard deviation is nearly $50 \%$ greater than that from the snow-radar observations.

\subsection{Elevation-Dependent Accumulation Gradients}

[14] To investigate spatial accumulation distributions further, we compared the relationship between elevation and accumulation for each data set (Figure 4). All models underestimate accumulation at the highest elevations: modeled accumulation declines more rapidly with elevation than is observed. Although the models show a slight overestimation of accumulation below $1000 \mathrm{~m}$, the radar

Table 1. Time Series Statistics and Spatial and Temporal Correlation Coefficients $(r)$

\begin{tabular}{|c|c|c|c|c|c|c|c|c|}
\hline & & Snow Radar & $\mathrm{RACMO}^{\mathrm{c}}$ & ERA-Int ${ }^{\mathrm{c}}$ & $\mathrm{CFSR}^{\mathrm{c}}$ & MERRA $^{\mathrm{c}}$ & 2010 Cores & ITASE Cores $^{\mathrm{d}}$ \\
\hline \multirow[t]{2}{*}{ Time Series Statistics ${ }^{\mathrm{a}}$} & $\mu \pm \sigma\left(\mathrm{m}\right.$ w.e. $\left.\mathrm{yr}^{-1}\right)$ & $0.457 \pm 0.055$ & $0.434 \pm 0.080$ & $0.382 \pm 0.056$ & $0.407 \pm 0.060$ & $0.346 \pm 0.057$ & $0.377 \pm 0.049$ & $0.401 \pm 0.053$ \\
\hline & $m$ (\% per decade $)$ & $-0.3 \pm 5.4 \%$ & $+1.1 \pm 8.2 \%$ & $-1.5 \pm 6.5 \%$ & $+0.5 \pm 6.6 \%$ & $+2.1 \pm 7.3 \%$ & $-0.1 \pm 5.7 \%$ & $-1.2 \pm 9.5 \%$ \\
\hline \multirow[t]{7}{*}{ Correlation Matrix $^{\mathrm{b}}$} & Snow Radar & -- & 0.86 & 0.68 & 0.75 & 0.75 & & \\
\hline & $\mathrm{RACMO}^{\mathrm{c}}$ & 0.68 & -- & 0.78 & 0.86 & 0.86 & & \\
\hline & ERA-Int $^{\mathrm{c}}$ & 0.93 & 0.69 & -- & 0.91 & 0.78 & & \\
\hline & $\mathrm{CFSR}^{\mathrm{c}}$ & 0.91 & 0.64 & 0.94 & -- & 0.85 & & \\
\hline & MERRA $^{c}$ & 0.92 & 0.69 & 0.91 & 0.93 & -- & & \\
\hline & 2010 Cores & 0.80 & 0.64 & 0.79 & 0.81 & 0.77 & -- & \\
\hline & ITASE Cores ${ }^{\mathrm{d}}$ & 0.80 & 0.64 & 0.69 & 0.73 & 0.72 & 0.66 & -- \\
\hline
\end{tabular}

\footnotetext{
${ }^{\mathrm{a}}$ The mean $(\mu)$, standard deviation $(\sigma)$, and trend slope $(m)$ with $95 \%$ confidence intervals during $1980-2009$.

${ }^{b}$ Upper right italicized (lower left bolded) corner contains the spatial (temporal) correlation coefficients. All $r$ are statistically significant at the $99 \%$ confidence level.

${ }^{c}$ Model grid resolution approximated over Thwaites Glacier: $27 \mathrm{~km}$ (RACMO2), $\sim 80 \mathrm{~km}$ (ERA-Int), $38 \mathrm{~km}$ (CFSR), 55 × $20 \mathrm{~km}$ (MERRA).

${ }^{\mathrm{d}}$ ITASE Cores 01-1, 01-2, and 01-3; Statistics calculated over the period of record (1980-2001).
} 


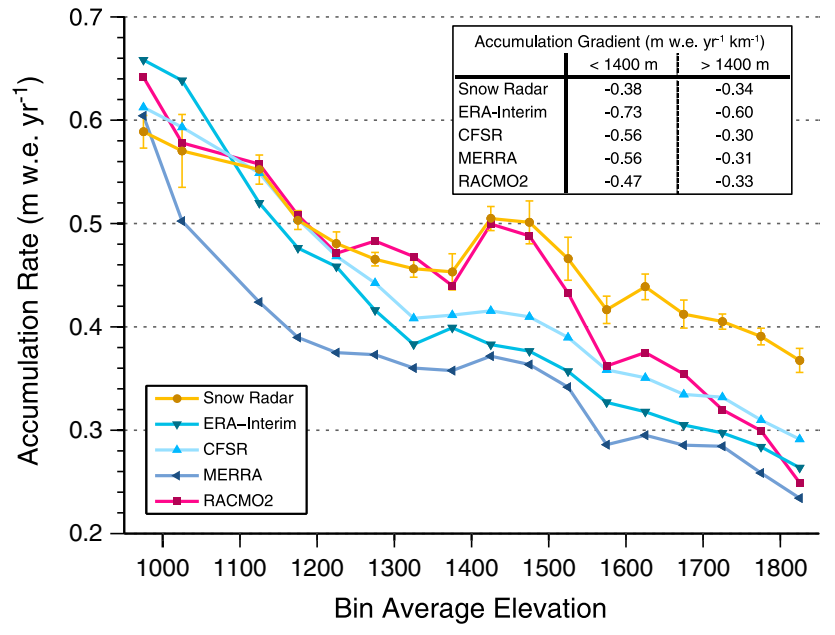

Figure 4. Snow-radar (orange circle), RACMO2 (red square), and reanalysis (blue triangles) accumulation rates averaged over $50 \mathrm{~m}$ elevation bins. Inset table contains the accumulation gradients (linear) above and below $1400 \mathrm{~m}$ for each data set. Accumulation rates generally decrease with increasing elevation for all data sets. RACMO2 is the most capable of reproducing the small-scale features found in the snow-radar profile. The three global reanalyses all underestimate accumulation, with potential exceptions at the lowest elevations where there is insufficient sampling.

sampling at these elevations is not sufficient to confidently interpret the differences. To quantify discrepancies, elevation-dependent accumulation gradients are approximated by a linear fit to the data in Figure 4 and are listed in the inset table. We find RACMO2 captures much of the spatial variability in accumulation because of its finer spatial resolution but does not perform as well above $1400 \mathrm{~m}$ in this region as at lower elevations. The global models adequately capture the regional-scale variability in accumulation, even with their coarser spatial resolution, but the steep accumulation gradients below $1400 \mathrm{~m}$ indicate that not nearly enough accumulation is reaching moderate to high elevations.

\section{Discussion}

[15] The snow-radar record, ice core ensembles, and atmospheric models do not show any significant trend in accumulation over Thwaites basin between 1980 and 2009 indicating that the recent increase in ice discharge from the region has not been simultaneously compensated by a comparable increase in accumulation. The trends in accumulation range between -1.5 and $+2.1 \%$ per decade and are all statistically insignificant (Table 1). The MERRA trend of $+2.1 \%$ per decade is likely inflated due to data-assimilation artifacts [Bromwich et al., 2011]. The lack of a significant trend does not necessarily rule out a relationship between rising temperatures in West Antarctica and changing snow accumulation, considering the length and interannual variance of the accumulation record. A recent model simulation of Antarctic precipitation predicts a $2 \%$ per decade increase over the $21^{\text {st }}$ century [Genthon et al., 2009]. The 2- $\sigma$ sampling error associated with the short $(n=30)$ snow-radar record with high annual variability $(\sigma=12.0 \%)$ is $\pm 4.4 \%$ $\left(2 \sigma n^{-0.5}\right)$, indicating that a $2 \%$ per decade increase would not be detectable and cannot be ruled out. However, trend magnitudes greater than $5 \%$ per decade can be ruled out, which, when compared to the $\sim 11 \%$ per decade increase in Thwaites ice discharge [Rignot, 2008], confirms that the accumulation trend is not keeping pace with changes in ice dynamics.

[16] Our results indicate that the snow radar provides a reliable annual signal over the Thwaites basin and provides high-quality accumulation rate measurements independent of ice core glaciochemical analysis. The high correlations between the radar- and core-derived annual accumulation records confirm our interpretation of a snow-radar annual signal, highlighting the potential of radar profiling for mass balance studies. Qualitative analysis of the radar data suggests that the snow radar is most suitable where average accumulation rates are between 0.3 and $0.6 \mathrm{~m}$ w.e. $\mathrm{yr}^{-1}$. Outside these bounds, layers can still be resolved but not annually (based on data from systems operated in 20092011), making this method useful for estimating accumulation where independent age-depth information is available. The snow-radar method also serves as a much-needed means to improve model mass balance assessments through validation of and discrimination among the results from different models.

[17] These radar-derived accumulation rates provide the data necessary to evaluate the temporal variability of modeled accumulation rates at a regional scale. Our results show that models of accumulation are reasonable substitutions in areas lacking measurements. Although the global models underestimate the magnitude of accumulation by as much as $24 \%$, these models capture the interannual accumulation variability with high fidelity. The finer-resolution regional model underestimates the mean accumulation by only $5 \%$ and more accurately captures the spatial accumulation variability and elevation-dependent gradient. The differences between the global and regional models are likely related to differences in observational constraints. The reanalyses are constrained with global observations, including observations within Antarctica, which help capture temporal variability in accumulation. By contrast, RACMO2 is forced by the observation-driven ERA-Interim reanalysis product far from the continent and is thus not as well constrained by observations from Antarctica, yielding greater uncertainty in temporal variation. Additional snow-radar observations in Greenland and Antarctica through ongoing IceBridge campaigns will provide the constraints necessary for further refinement and improvement to these atmospheric models.

\section{Conclusion}

[18] Comparisons of new radar-derived observations of ice sheet accumulation, ice core records, and model data demonstrate that: (1) ultra-wideband microwave radars provide accurate and independent estimates of accumulation; and (2) both global and regional models reasonably account for the variability, while the global models underestimate the magnitude of accumulation in this sector of West Antarctica. We find that Thwaites Glacier has not experienced a statistically significant change in accumulation over the past three decades. Therefore, the recent increase in ice 


\section{MEDLEY ET AL.: SNOW ACCUMULATION OVER THWAITES GLACIER}

discharge from the glacier has not been balanced by a simultaneous increase in accumulation.

[19] Acknowledgments. We thank S. Arcone and an anonymous reviewer for their constructive comments. This research was supported at UW by NSF OPP grants ANT-0631973 (B.M., I.J., E.J.S., and H.C.) and ANT-0424589 (B.M. and I.J.) and at WHOI by ANT-0632031 (S.B.D. and A.S.C.). D.H.B. and J.P.N. were supported by NASA grant NN12XAI29G. We acknowledge the work by the CReSIS team that went into developing the snow-radar system, which was partially supported with by NASA grant NNX10AT68G and by NSF OPP grant ANT-0424589 awarded to S.P. We acknowledge the efforts of the students and staff of the ultra-trace chemistry laboratory at the Desert Research Institute in analyzing the ice cores. We thank L. Albershardt, L. Trusel, the U.S Antarctic Program, and the U.S. Ice Drilling Program. This article is contribution 1433 of the Byrd Polar Research Center.

\section{References}

Arcone, S. A., V. B. Spikes, G. S. Hamilton, and P. A. Mayewski (2004), Stratigraphic continuity in $400-\mathrm{MHz}$ radar profiles in West Antarctica, Ann. Glaciol., 39(1), 195-200, doi:10.3189/172756404781813925.

Arcone, S. A., V. B. Spikes, and G. S. Hamilton (2005a), Phase structure of radar stratigraphic horizons within Antarctic firn, Ann. Glaciol., 41(1), 10-16, doi:10.3189/172756405781813267.

Arcone, S. A., V. B. Spikes, and G. S. Hamilton (2005b), Stratigraphic variation in polar firn caused by differential accumulation and ice flow: Interpretation of a $400-\mathrm{MHz}$ shortpulse radar profile from West Antarctica, J. Glaciol., 51(7), 407-422, doi:10.3189/ 172756505781829151.

Arthern, R. J., D. P. Winebrenner, and D. G. Vaughan (2006), Antarctic snow accumulation mapped using polarization of $4.3-\mathrm{cm}$ wavelength microwave emission, J. Geophys. Res., 111, D06107, doi:10.1029/ 2004JD005667.

Bamber, J. L., J. Gomez-Dans, and J. A. Griggs (2009), A new 1 km digital elevation model of the Antarctic derived from combined satellite radar and laser data Part 1: Data and methods, Cryosphere, 3(1), 101-111, doi:10.5194/tc-3-101-2009.

Banta, J. R., J. R. McConnell, M. M. Frey, R. C. Bales, and K. Taylor (2008), Spatial and temporal variability in snow accumulation at the West Antarctic Ice Sheet Divide over recent centuries, J. Geophys. Res., 113, D23102, doi:10.1029/2008JD010235.

Bromwich, D. H., J. P. Nicolas, and A. J. Monaghan (2011), An Assessment of Precipitation Changes over Antarctica and the Southern Ocean since 1989 in Contemporary Global Reanalyses, J. Clim, 24(16), 4189-4209. doi:10.1175/2011JCLI4074.1.

Bromwich, D. H., J. P. Nicolas, A. J. Monaghan, M. A. Lazzara, L. M. Keller, G. A. Weidner, and A. B. Wilson (2013), Central West Antarctica among the most rapidly warming regions on Earth, Nat. Geosci., 6(2), 139-145.

Dee, D. P. et al. (2011), The ERA-Interim reanalysis: configuration and performance of the data assimilation system, $Q$. J. R. Meteorolog. Soc., 137(656), 553-597, doi:10.1002/qj.828

Genthon, C., G. Krinner, and H. Castebrunet (2009), Antarctic precipitation and climate-change predictions: horizontal resolution and margin vs plateau issues, Ann. Glaciol., 50(50), 55-60, doi:10.3189/ 172756409787769681.

Haran, T., T. Bohlander, T. Scambos, T. Painter, and M. A. Fahnestock compilers (2005), MODIS mosaic of Antarctica (MOA) image map. Boulder, Colorado USA: National Snow and Ice Data Center, doi:10.7265/N5ZK5DM5.

Herron, M. M., and C. C. Langway (1980), Firn densification: an empirical model, J. Glaciol., 25, 373-385.

Kanagaratnam, P., S. P. Gogineni, V. Ramasami, and D. Braaten (2004), A wideband radar for high-resolution mapping of near-surface internal layers in glacial ice, IEEE Trans. Geosci. Remote Sens., 42(3), 483-490.
Kaspari, S., P. A. Mayewski, D. A. Dixon, V. B. Spikes, S. B. Sneed, M. J. Handley, and G. S. Hamilton (2004), Climate variability in West Antarctica derived from annual accumulation-rate records from ITASE firn/ice cores, Ann. Glaciol., 39(1), 585-594, doi:10.3189/ 172756404781814447 .

Lenaerts, J. T. M., M. R. van den Broeke, W. J. van de Berg, E. van Meijgaard, and P. Kuipers Munneke (2012), A new, highresolution surface mass balance map of Antarctica (1979-2010) based on regional atmospheric climate modeling, Geophys. Res. Lett., 39, L04501, doi:10.1029/2011GL050713.

Leuschen, C. (2010), IceBridge Snow Radar L1B Geolocated Radar Echo Strength Profiles. October 18, 2009, November 19, 2010, November 9 \& 12, 2011. Boulder, Colorado USA: NASA DAAC at the National Snow and Ice Data Center.

Looyenga, H. (1965), Dielectric constants of heterogeneous mixtures, Physica, 31(3), 401-406, doi:10.1016/0031-8914(65)90045-5.

Maselli, O., D. Fritzche, L. Layman, J. McConnell, and H. Meyer (2013), Comparison of water isotope ratio determinations using two cavity ringdown instruments and classical mass spectrometry in continuous icecore analysis, Isot Environ. Health Stud., in press.

McConnell, J. R., G. W. Lamorey, S. W. Lambert, and K. C. Taylor (2002), Continuous Ice-Core Chemical Analyses Using Inductively Coupled Plasma Mass Spectrometry, Environ. Sci. Technol., 36(1), 7-11, doi:10.1021/es011088z.

McConnell, J. R. et al. (2007), 20th-Century Industrial Black Carbon Emissions Altered Arctic Climate Forcing, Science, 317(5843), 1381-1384, doi:10.1126/science.1144856.

Monaghan, A. J., D. H. Bromwich, and S. Wang (2006), Recent trends in Antarctic snow accumulation from Polar MM5 simulations, Phil. Trans. R. Soc. A, 364(1844), 1683-1708, doi:10.1098/rsta.2006.1795.

Orsi, A. J., B. D. Cornuelle, and J. P. Severinghaus (2012), Little Ice Age cold interval in West Antarctica: Evidence from borehole temperature at the West Antarctic Ice Sheet (WAIS) Divide, Geophys. Res. Lett., 39, L09710, doi:10.1029/2012GL051260.

Panzer, B., et al. (2013), An ultra-wideband, microwave radar for measuring snow thickness on sea ice and mapping near-surface internal layers in polar firn, J. Glaciol., 59(214), 244-254, doi:10.3189/ 2013JoG12J128.

Rienecker, M. M., et al. (2011), MERRA: NASA's Modern-Era Retrospective Analysis for Research and Applications, J. Clim., 24(14), 3624-3648, doi:10.1175/JCLI-D-11-00015.1.

Rignot, E. (2008), Changes in West Antarctic ice stream dynamics observed with ALOS PALSAR data, Geophys. Res. Lett., 35, L12505, doi:10.1029/ 2008 GL033365.

Rignot, E., J. L. Bamber, M. R. van den Broeke, C. Davis, Y. Li, W. J. van de Berg, and E. van Meijgaard (2008), Recent Antarctic ice mass loss from radar interferometry and regional climate modelling, Nat. Geosci., 1(2), 106-110.

Rodriguez-Morales, F., et al. (2013), Advanced Multi-Frequency Radar Instrumentation for Polar Research, IEEE Trans. Geosci. Rem. Sens, in press.

Saha, S., et al. (2010), The NCEP Climate Forecast System Reanalysis, Bull. Am. Meteorol. Soc., 91(8), 1015-1057, doi:10.1175/2010BAMS3001.1.

Shepherd, A., et al. (2012), A Reconciled Estimate of Ice-Sheet Mass Balance, Science, 338(6111), 1183-1189, doi:10.1126/science.1228102.

Spikes, V. B., G. S. Hamilton, S. A. Arcone, S. Kaspari, and P. A. Mayewski (2004), Variability in accumulation rates from GPR profiling on the West Antarctic plateau, Ann. Glaciol., 39, 238-244, doi:10.3189/ 172756404781814393

Steig, E. J., D. P. Schneider, S. D. Rutherford, M. E. Mann, J. C. Comiso, and D. T. Shindell (2009), Warming of the Antarctic ice-sheet surface since the 1957 International Geophysical Year, Nature, 457(7228), 459-462.

van de Berg, W. J., M. R. van den Broeke, C. H. Reijmer, and E. van Meijgaard (2005), Characteristics of the Antarctic surface mass balance, 1958-2002, using a regional atmospheric climate model, Ann. Glaciol., 41(1), 97-104, doi:10.3189/172756405781813302. 